\title{
Evolution of Mesoscale Convective Systems and its Relationship with the Madden-Julian Oscillation in the Indo-Pacific Region
}

\author{
Ahmed Salahuddin* and Scott Curtis
}

\author{
Department of Geography, Atmospheric Science Laboratory, East Carolina University, USA
}

\begin{abstract}
In this study we investigated the influence of sea surface temperature (SST) and Madden-Julian Oscillation (MJO) on the organization, strength, and distribution of Mesoscale Convective Systems (MCSs) over the Indo-Pacific region for understanding El Nino Southern Oscillation (ENSO). The study is based on the Tropical Rainfall Measuring Mission's (TRMM) precipitation features dataset during boreal winters of 2001-02 to 2006-07. The results of time series of hot spot analyses show that MCSs are predominantly clustered in the Maritime Continent and West Pacific Regions, and are preferentially observed over ocean compared to land. The largest quantity of MCSs were observed to the south of the equator in January 2002, and the distribution of MCSs as a function of SST for these months peaked between 29-30 Celsius. MJO explains $11 \%$ to nearly $30 \%$ of the characteristics of MCSs in the Indo-Pacific. The percentage of MCSs over the ocean in January is larger when the MJO is in the active phase than the passive phase from the Indian Ocean to the West Pacific Region. The warm waters under the MCSs may be related to the coupled MJO process that convectively generate and maintain the storms. The effect of the MJO is strongest when it is located within the Maritime Continent region. The MJO analysis indicates that MCSs are more likely accompanied by westerly winds during the eastward propagation of the MJO and the westerly wind bursts have been linked to the onset of El Nino in the Pacific.
\end{abstract}

Keywords: MCS, Madden-Julian Oscillation, SST, precipitation feature, hot spot.

\section{INTRODUCTION}

Mesoscale convective systems produce heavy rainfall organized at larger scales and play an overarching role in intraseasonal and interannual climate variability in the IndoPacific region. The climate of the region is also influenced by the sea, for example the El Nino Southern Oscillation (ENSO), one extreme oceanic event characterized by a warm central and eastern Pacific Ocean and enhanced atmospheric pressure over Australia and the Indo-Pacific sector. Precipitation information is critical for understanding the hydrologic balance as well as understanding the complex interactions among the components within the hydrologic cycle.

Intraseasonal variability is important to the evolution of the ENSO [1]. On the role between intraseasonal variations (ISV) and El Nino, Curtis and Salahuddin [2] found that a signal of precipitation and westerly wind with a particular frequency of 3 cycles per season propagated eastward in the Indo-Pacific region during boreal winters prior to the 199798 and 2002-03 El Ninos. Houze [3] defined mesoscale convective system (MCS) as a cloud system that occurs in connection with an ensemble of thunderstorms and produces a contiguous precipitation area about $100 \mathrm{~km}$ or more in horizontal scale in at least one direction. Later Nesbitt et al. [4] defined MCS as a contiguous area having near-surface precipitation reflectivity $\geq 20 \mathrm{dBZ}$ or TMI $85 \mathrm{GHz}$ PCT $\leq$ $250 \mathrm{~K}$ to be contained within the rain or ice scattering area of

*Address correspondence to this author at the Department of Geography, Atmospheric Science Laboratory, East Carolina University, USA; Tel: 252328-4993; Fax: 252-328-6054;

E-mails: salahuddina@ecu.edu, s_uddin2002@yahoo.com the system. Studies [5,6] found that mesoscale convective systems (MCSs) are an important contributor to global rainfall and a key component in the preservation of the global atmospheric circulation through latent heating. Lately, Zipser et al. [7] detected the location of extreme intense thunderstorms using Tropical Rainfall Measuring Mission (TRMM) data. But none of these studies fully confront the intraseasonal variations of MCSs in the Indo-Pacific region on the interannual scale. Therefore, we focus this study on the diagnosis of the Madden-Julian Oscillation, an equatorial disturbance discovered in the 1970's [8,9] that affects the intensity and frequency of precipitation features from the Indian Ocean to the western Pacific region. The deep convection in the western part of the Maritime Continent is not only affected by the MJO, but also the Borneo vortex, and northeast cold surges [10]. Tangang et al. [11] related these various systems with extreme precipitation events in southern Peninsular Malaysia.

The central hypothesis of the research is that mesoscale convective systems contribute to extreme precipitation locally, are organized by the Madden-Julian Oscillation, which is in turn connected to El Nino development and drought in the Maritime Continent (Fig. 1). The process that couples the land, ocean and atmosphere take place in association with multiple interacting space and timescales. Typical rain producing weather systems are within the mesoscale and central to local hydrology. The mesoscale convective systems are in turn organized at the regional scale by intraseasonal climate variability manifested by the Madden-Julian Oscillation. Finally, at the global scale the Maritime Continent is the birthplace of ENSO as the Madden-Julian Oscillation triggers climate change in the 


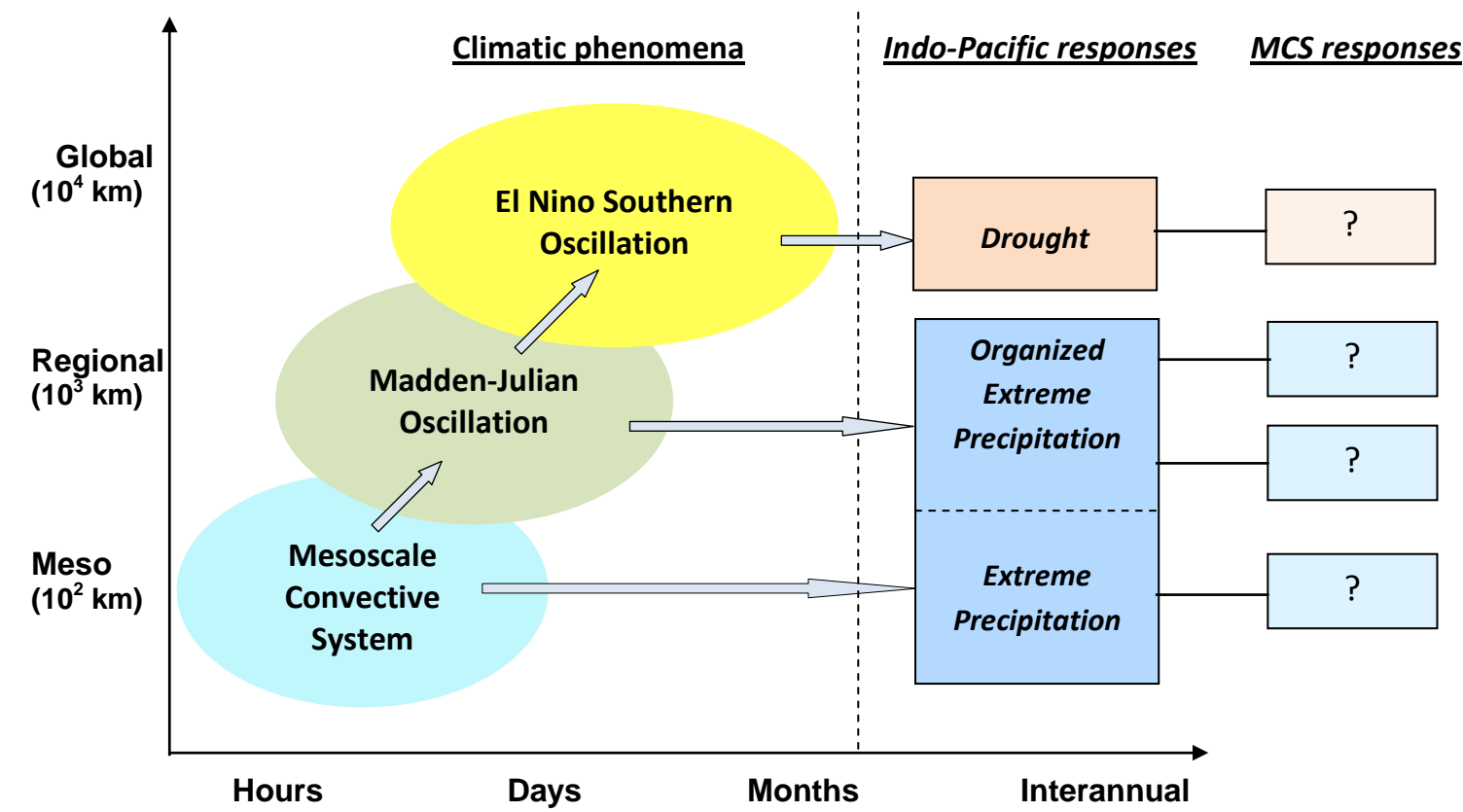

Fig. (1). Simplified schematic diagram of the key climate phenomena and impacts in the Maritime Continent from Mesoscale Convective Systems to El Nino Southern Oscillation. The arrow indicates the transformation of phenomenon and scale interactions from one scale to another.

Pacific Ocean through westerly wind induced oceanic Kelvin waves.

MJO activity has largely been observed around $10^{\circ}$ off the equator in the western Pacific and a significant relationship between MJO and ENSO activity was recently reported by Tang and $\mathrm{Yu}$ [12]. Also MJO is associated with strong sea surface temperature (SST) variability locally [13]. Finally, a mature ENSO entails a shift in the Walker Circulation, which brings drought to the Maritime Continent. In the light of these interacting climate phenomena the major objectives of this study are as follows: (i) examine the role and influence of land-sea-atmosphere interactions on the overall climate of the Indo-Pacific region, and (ii) diagnose the intraseasonal variability of precipitation features over the Indo-Pacific region. The questions to be addressed include (a) what is the regional MCS climatology in the Indo-Pacific region and (b) how does the Madden-Julian Oscillation affect the intensity and frequency of precipitation features.

The study domain, data, and methodology will be described in section 2. Section 3 provides the sea surface temperature analysis throughout the region. Section 4 is devoted to the pentad time series analysis and section 5 provides the results of $\mathrm{MJO}$ with interpretation of the data based largely on the correlation among the precipitation feature properties on land and ocean. Section 6 summarizes the major findings. In the last section some concluding remarks are made.

\section{DATA AND METHODOLOGY}

The domain extents geographically from $26^{\circ} \mathrm{N}$ to $26^{\circ} \mathrm{S}$ and $50^{\circ} \mathrm{E}$ to $180^{\circ}$ and includes the Indian Ocean and West Pacific Ocean (Fig. 2). Within the domain the Maritime Continent countries are highlighted. The research domain and problem have implications beyond the boundary of climate science. The primary advantage of this research outcome is to predict the ENSO in advance so that associated economic and social loss may be reduced. Extreme rainfall events along the coast may be a predictor for ENSO [14] and they themselves largely affect coastal agriculture and ecosystems. Rainfall at the coast may affect the fish population and livelihood of the indigenous populations. Therefore, it is important to understand the climate science in the MC region as it transforms from small-scale (mesoscale convective systems) to the large-scale (ENSO).

\section{a. The TRMM Satellite and Precipitation Features}

In order to identify the discrete precipitation features in the Indo-Pacific region the study used Tropical Rainfall Measuring Mission's (TRMM) precipitation feature dataset (courtesy C. Liu). The launch of the TRMM satellite on November 27, 1997 instigated an era that significantly improved the quantitative description of tropical precipitation systems. TRMM orbits at approximately 350 $\mathrm{km}$ altitude with $35^{\circ}$ inclination from the equatorial plane. The TRMM Precipitation Radar (PR) data allow 3D retrievals of radar reflectivity and precipitation rate revealing the horizontal and vertical structure of precipitation systems ranging $35^{\circ} \mathrm{N}$ to $35^{\circ} \mathrm{S}$ latitude. The PR has also gathered high quality precipitation data over the ocean for the first time. The active and passive sensors flown on a single platform and its orbital characteristics make TRMM unique [7]. The precipitation feature definition used in this study groups pixels with near-surface precipitation reflectivity > $20 \mathrm{dBZ}$ or TMI $85.5 \mathrm{GHz}$ PCT below $250 \mathrm{~K}$. Polarization corrected temperatures have been calculated at $85 \mathrm{GHz}$ to remove effects of surface emissivity variations over ocean and land surfaces:

$$
P C T=\frac{\beta T_{b H}-T_{b V}}{\beta-T}
$$




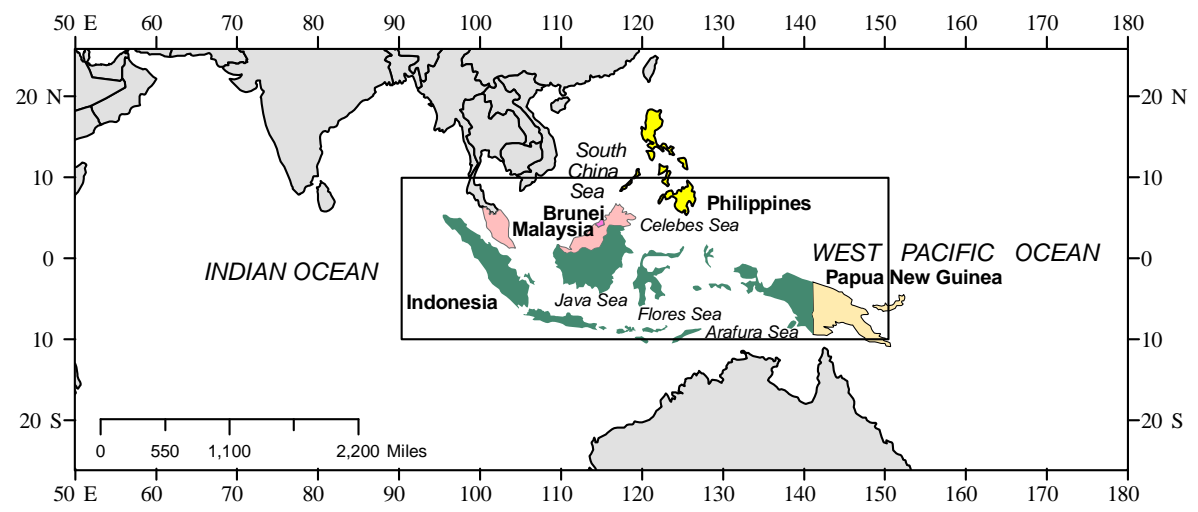

Fig. (2). the Indo-Pacific study region. It extends geographically from $50^{\circ} \mathrm{E}$ to $180^{\circ}$ and $26^{\circ} \mathrm{N}$ to $26^{\circ} \mathrm{S}$ comprising the East Indian Ocean to the West Pacific Ocean. The rectangular domain represents the Maritime Continent.

The horizontally and vertically polarized channels are used ( $T_{b H}$ and $T_{b V}$, respectively) to calculate $85 \mathrm{PCT}$; the value for $\beta$ is 0.45 at $85 \mathrm{GHz}$ [15].

\section{b. Datasets and Operational Altitude Change}

TRMM data from December to February of 2001 through 2007 is selected for the study. The precipitation features used in this study come from algorithm TRMM 2A25. The sea surface temperature (SST) data are based on the TRMM Microwave Imager (TMI) developed by the Remote Sensing Systems (RSS). The Quick Scatterometer (QuikSCAT) wind data are downloaded from the Remote Sensing Systems website http://www.ssmi.com/qscat/qscat_description.html. The advantage of the scatterometer is measurement of winds near the ocean surface. The SST and QuickSCAT data are at a 0.25 degree spatial $(\sim 25 \mathrm{~km})$ and a daily temporal resolution.

The criteria for precipitation features is summarized in Table 1, and the dataset includes the following properties [4].

- $\quad$ Geolocation and time: year, month, day, hour, center longitude, latitude, elevation, over land or ocean(1/0), orbit number.

- Measurements: number of pixels, maximum $20 \mathrm{dBz}, 30 \mathrm{dBz}, 40 \mathrm{dBz}$ height, maximum reflectivity at $6 \mathrm{~km}, 9 \mathrm{~km}$, maximum storm height, maximum near surface reflectivity, minimum TMI $37 \mathrm{GHz}, 85 \mathrm{GHz}$ PCT, minimum IR temperature, flash counts, flash rates, number of pixels with $85 \mathrm{GHz}$ PCT colder than $250 \mathrm{~K}$, $225 \mathrm{~K}, 200 \mathrm{~K}, 175 \mathrm{~K}, 150 \mathrm{~K}, 125 \mathrm{~K}, 100 \mathrm{~K}$.
- Retrievals:

volumetric rain from PR (2A25), volumetric rain from TMI (2A12), number of pixels with $2 \mathrm{~A} 12$ rain, convective/stratiform volumetric rain, number of pixels with convective/stratiform rain.

The recent satellite-based observations of precipitation, sea surface temperature and ocean surface winds can be used to examine ocean-atmosphere interactions in tropical regions, and the high resolution is important to understand the complex geographic variations in the Maritime Continent. This study addresses boreal seasons, 2001 to 2007. The reason for considering this period is the abrupt shift in MCS characteristics due to a data bias after the TRMM boost to a higher orbit. Increasing the operative altitude from $350 \mathrm{~km}$ to $402.5 \mathrm{~km}$ on August 7, 2001 caused a $15 \%$ increase in the size of the footprint. The boost has significantly extended the satellite's life, which continues to provide meteorologists and climatologists data to forecast and better understand global climate change. The TRMM satellite collects data on rainfall and the heat release associated with rainfall, as well as information about interactions between water vapor, clouds and precipitation that are central to regulating the climate system. From a science standpoint, an extended mission provides a more robust climate record of rainfall. It also provides scientists with an opportunity to capture additional information about the global changes of rainfall in the events of El Nino and La Nina. Operational centers like the NOAA's National Hurricane Center and the Department of Defense's Joint Typhoon Warning Center (JTWC) can continue to use TRMM data for hurricane identification and monitoring. Additionally, NOAA's National Center for Environmental

Table 1. Listing of Criteria for Precipitation Features*

\begin{tabular}{|c|c|c|c|c|}
\hline $\begin{array}{c}\text { Array of } \\
\text { Indices }\end{array}$ & Features & Criteria & $\begin{array}{c}\text { Minimum Number of Pixels } \\
\text { Pre-Boost }\end{array}$ & $\begin{array}{c}\text { Minimum Number of Pixels } \\
\text { Post-Boost }\end{array}$ \\
\hline \hline grptpf & $\begin{array}{c}\text { Precipitation Feature } \\
\text { (PF) }\end{array}$ & $\begin{array}{c}\text { PR Near surface reflectivity } \geq 20 \mathrm{dBZ} \text { or } \\
\text { TMI } 85 \mathrm{GHz} \text { PCT } \leq 250 \mathrm{~K}\end{array}$ & 1 & 1 \\
\hline grpmcs & $\begin{array}{c}\text { Mesoscale Convective } \\
\text { System (MCS) }\end{array}$ & $\begin{array}{c}\text { TMI 85 GHz PCT } \leq 250 \mathrm{~K} \text { (contiguous) } \\
\text { TMI 85 GHz PCT } \leq 225 \mathrm{~K}\end{array}$ & 108 & 10 \\
\hline grpint & Intense MCS & TMI 85 GHz PCT $\leq 200 \mathrm{~K}$ (contiguous) & 108 & 82 \\
\hline
\end{tabular}

* Adopted from http://www.met.utah.edu/zipser/pub/projects/trmm/variables.html 
Prediction (NCEP) and the European Center for Medium Range Weather Forecasting (ECMWF) have begun to test TRMM data in weather forecasts models, such that an extension of TRMM mission life has potential future benefits in weather forecasting.

The dataset used in this study are summarized in Table 2. Zonal wind is computed from wind speed and direction and was averaged over the calendar month. Remote Sensing Systems uses four satellite microwave radiometers (F13 SSMI, F14 SSMI, F15 SSMI, and TMI) to determine if rain is present at the location of the QuikScat observation. This monthly zonal wind and SST was recorded under each precipitation feature and land/ocean, $20 \mathrm{dBz}$ height, 85 PCT, and volumetric rain were selected for the study. $20 \mathrm{dBz}$ height determines the altitude of hydrometeors and thus how convective the cloud system and TMI $85 \mathrm{GHz}$ PCT is used to identify anvils contained within the rain or ice scattering area of the system. The former variable is positively related and the latter variable negatively related to MCS intensity.

\section{c. Methodology}

A Geographic Information System (GIS) -based mapping methodology is performed for the analysis of the surface data. The GIS-based method is used to explore and identify the strength and spatial distribution of the parameters in the Indo-Pacific region on the interannual and intraseasonal timescales. To this extent ArcCatalog and ArcTool box version 9.2 embedded into ArcGIS (version 9.2) are extensively used for file conversion, data extraction and spatial and temporal investigation of mesoscale convective systems. GIS mapping software combined with a spatial database is used for analysis of multiple layers of information for a particular geographic location of the domain. Spatial technology is highly preferred in order to display the multiple variables and layers of information over the Indo-Pacific region. A simple linear regression model with $95 \%$ confidence interval relates the MJO with MCS counts and characteristics and $\mathrm{p}$ values are automatically derived from the analysis. In order to investigate the climatology of the study region the MCSs counts, kernel density distribution, and hot spots are used for all boreal winter months (December -February) from 2001-02 to 200607. The details and justification of using these parameters of the MCSs are as follows:

\section{d. MSCs Count}

MCS count is one of the typologies of cluster analysis used in this research. The typology is the most intuitive type of cluster involving the number of MCSs observed at different areas in the Indo-Pacific. The total number of MCS counts is quantified on the basis of $\mathrm{X}$ and $\mathrm{Y}$ coordinate locations of each precipitation feature.

\section{e. Kernel Density Distribution}

The kernel density distribution involves placing a symmetrical surface over each point, evaluating the distance from the point to a reference location based on a mathematical function, and summing the value of all surfaces at that reference location. It produces a smoothed, continuous intensity surface of a point pattern (see formula). In this method at any point on the surface, the intensity is determined by identifying the points near it, and weighting them based on their distance. The weighting is achieved using a 'kernel' function, such as Gaussian curve. The nearest points are given more weight in this method. This technique was developed in late $1950 \mathrm{~s}$ as an alternative method for estimating the density of a histogram [16-18]. The single kernel density estimator under the spatial modeling technique of normal distribution is used to compute the absolute density of MCSs over a $2^{\circ}$ grid.

$$
f(x)=\frac{1}{n} \sum_{i=1}^{n} K\left(\frac{x-x(i)}{h}\right)
$$

where $\int K(t) d t=1$ to ensure that the estimate integrates to 1 and where the kernel function $K$ is usually chosen to be a smooth unimodal function with a peak at 0 .

\section{f. Standard Deviational Ellipses of Hot Spots of MCSs}

Hot spot areas are concentrations of MCSs within a geographical boundary at a particular time. The hot spot analysis method counts the number of MCSs falling within each circle, and ranks the circles in descending order. The process is repeated in order to avoid overlapping circles. A scan-type clustering algorithm, Spatial and Temporal Analysis of Crime (STAC) software integrated into CrimeStat, is performed to identify hot spot areas $[19,20]$. In the hot spot method all points are assigned to clusters and are displayed as deviational. It may not contain every hot cluster point. The boundaries of the ellipses are displayed as mapped layers by standard GIS Arcmap software. The standard deviational ellipse is derived from the bivariate distribution and is mathematically defined by

Bivariate distribution $=\left[\left(\sigma 1_{\mathrm{x}}+\sigma 2_{\mathrm{y}}\right) / 2\right]^{0.5}$

The two standard deviations, in the $\mathrm{X}$ and $\mathrm{Y}$ directions, are orthogonal to each other and define an ellipse. By

Table 2. Listing of Variables with their Temporal Coverage, Resolution, and Sources

\begin{tabular}{|c|c|c|c|c|c|}
\hline Variables & $\begin{array}{c}\text { Data } \\
\text { Sources }\end{array}$ & $\begin{array}{l}\text { Temporal } \\
\text { Coverage }\end{array}$ & $\begin{array}{l}\text { Temporal } \\
\text { Resolution }\end{array}$ & $\begin{array}{c}\text { Spatial } \\
\text { Resolution }\end{array}$ & Data Sources \\
\hline $\begin{array}{l}\text { Precipitation } \\
\text { Features }\end{array}$ & TRMM & $2001-2007$ & $\begin{array}{l}\text { Point observation } \\
\text { (TRMM orbital data) }\end{array}$ & & http://www.met.utah.edu/zipser/pub/projects/trmm \\
\hline $\begin{array}{l}\text { Sea Surface } \\
\text { Temperature }\end{array}$ & $\begin{array}{l}\text { TRMM \& } \\
\text { SSM/I }\end{array}$ & 2001-2007 & Daily & $0.25^{\circ}$ & http://www.ssmi.com \\
\hline Wind & QuikSCAT & 2001-2007 & Daily & $0.25^{\circ}$ & http://www.ssmi.com \\
\hline $\begin{array}{l}\text { Pentad MJO } \\
\text { Indices }\end{array}$ & $\begin{array}{l}\text { Outgoing Longwave } \\
\text { Radiation (OLR) }\end{array}$ & 1998-2007 & $\begin{array}{l}\text { Average over five } \\
\text { days }\end{array}$ & $20^{\circ}$ long & $\begin{array}{l}\text { http://www.cpc.ncep.noaa.gov/products/precip/C } \\
\text { Wlink/daily_mjo_index }\end{array}$ \\
\hline
\end{tabular}


convention, it is expressed as

$$
\theta=\tan ^{-1}\left(\Sigma\left(x_{i}-\bar{x}\right)^{2}-\Sigma\left(y_{i}-\bar{y}\right)^{2}+\sqrt{ } C / 2 \Sigma\left(x_{i}-\bar{x}\right)\left(y_{i}-\bar{y}\right)\right.
$$

where,$C=\left(\Sigma\left(x_{i}-\bar{x}\right)^{2}-\Sigma\left(y_{i}-\bar{y}\right)^{2}\right)^{2}+4 \Sigma\left(x_{i}-\bar{x}\right)\left(y_{i}-\bar{y}\right)^{2}$

and all summations are for $\mathrm{i}=1$ to $\mathrm{n}$

The mathematical expressions for the ellipse axis along the transposed $\mathrm{X}$-axis $\left(S D_{x}\right)$ and the ellipse axis along the transposed $\mathrm{Y}$-axis $\left(S D_{y}\right)$ are shown with $\mathrm{n}$ representing the number of precipitation features.

$$
\begin{aligned}
& \left.S D_{\mathrm{x}}=\left[2 \Sigma\left(x_{i}-\bar{x}\right) \cos \theta-\left(y_{i}-\bar{y}\right) \sin \theta\right)^{2} / \mathrm{n}-2\right]^{0.5} \\
& \left.S D_{\mathrm{y}}=\left[2 \Sigma\left(x_{i}-\bar{x}\right) \cos \theta-\left(y_{i}-\bar{y}\right) \sin \theta\right)^{2} / \mathrm{n}-2\right]^{0.5}
\end{aligned}
$$

The search radius is the key setting for defining the ellipses. In general, the larger the search radius, the more MCSs that will be included in each hot cluster and the larger the ellipse that will be displayed. Smaller search radius generally result in more ellipses of a smaller size. Initially, large radii are used and then areas that are 'hot' are reanalyzed with a smaller radius. For the general climatology of MCSs in the Indo-Pacific, a range of search radii were applied before deciding on a value of $500 \mathrm{~km}$.

\section{SEA SURFACE TEMPERATURE}

\section{a. Sea Surface Temperature and MCS Population}

The sea surface temperature is one of the most important diagnostic oceanographic parameters for monitoring global climate change since it lies at the interface of the ocean and atmosphere. The distribution of sea surface temperature from December through February of 2001-02 to 2006-07 revealed that the SST is highest in the West Pacific Region (WPR) and in the Maritime Continent (MC) (Fig. 3). The January histograms (Fig. 4a) clearly show that during January 2002 more MCSs were observed between $29^{\circ}$ and $30^{\circ} \mathrm{C}$ than for any other year. The MCS observations peaked in January 2002 among all 18 months (Fig. 4b). The percentage of MCS count was sorted by land and ocean and plotted during the 2001-02 to 2006-07 seasons and for January (Fig. 5). The average percent of MCS is greatest over the ocean (approximately 80 percent as compared to 20 percent) (Fig. 5). This is consistent with the findings of Schumacher and Houze [21] that tropical oceans have abundant populations of MCSs. There is an increase in the proportion of MCSs over land in 2003-04, while the lowest percentage is in 2001-02. This may be in part due to the Madden-Julian Oscillation (MJO). Therefore, the MCS concentrations need to be addressed in relation to MJO activity during boreal winter from the eastern Indian Ocean to the western Pacific Ocean. As we know on the basin scale, the western Pacific receives a higher precipitation rate than the Indian Ocean, where the highest rainfall occurs off the coast of Sumatra, Indonesia (Fig. 6). This matches well the pattern of SST (Fig. 3). The question remains as to whether warm surface waters control the spatial distribution and intensity of MCSs.

As investigated by Chou and Chou [22] the trade and monsoonal winds converge over the Maritime Continent inducing strong deep convection and producing a large amount of clouds. The hot spot analysis shows that in December MCSs are concentrated in the Maritime Continent region, which includes areas of Sumatra, Malaysia, Indonesia, Brunei, Papua New Guinea and part of the eastern Indian Ocean (Fig. 7a). In January the distribution of hot spots are found both in the eastern Indian Ocean (Fig. 7b) along with significant clustering over the WPR extending from the northern Australian coast to the Solomon Islands over the warmest waters. The western Pacific Ocean is warmer than the eastern Indian Ocean. However, the hot spots over ocean do not necessarily coincide with the warmest waters. The SST affects the surface evaporation and sensible heat flux over clear sky regions and determines the transport of water vapor convergence from clear sky regions to rainfall regions as mentioned by Vialard et al. [13]. This may be why the hot spots over ocean do not necessarily coincide with the warmest waters. Also the SST is greatly affected by the clouds in MCS by less solar radiative heating reaching on ocean surface and colder SST.

\section{MADDEN-JULIAN OSCILLATION}

The intraseasonal oscillation, Madden-Julian Oscillation (MJO), is a major component of the coupled oceanatmosphere system in both the lower and upper atmosphere that produces large and complex cloud systems that move from the Indian Ocean into the central Pacific Ocean at 5-10 $\mathrm{m} / \mathrm{s}$ with time scales from about 30-60 days [8,9]. These cloud systems directly affect tropical rainfall and formation of tropical storms. This section deals with the formation of

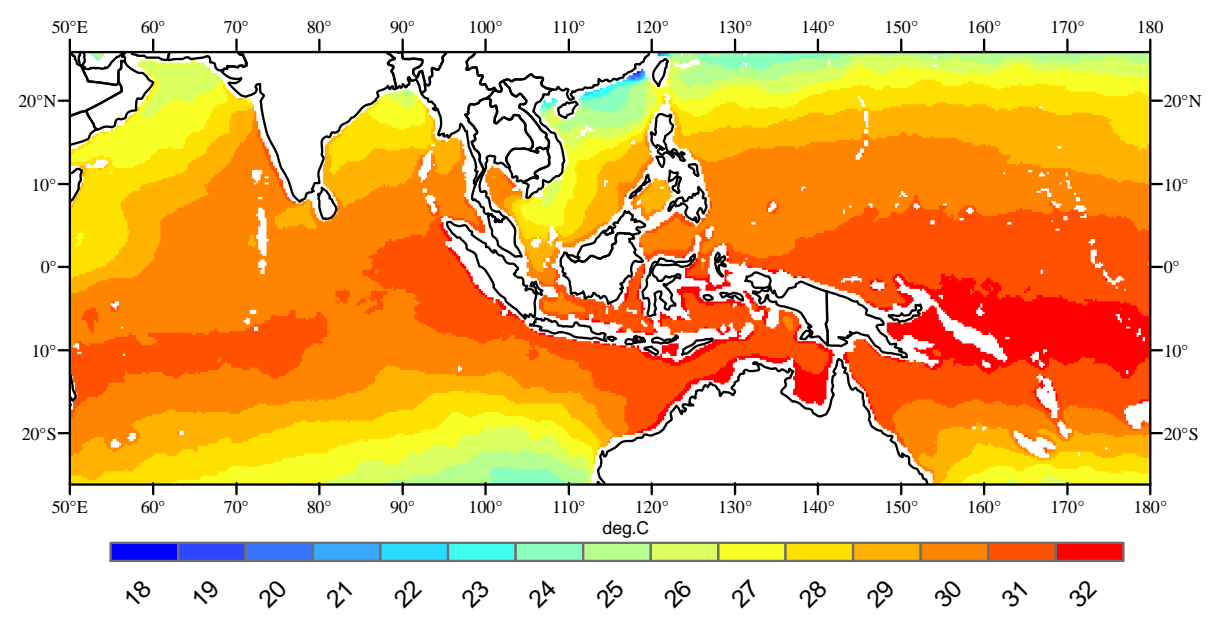

Fig. (3). Climatology of Indo-Pacific sea surface temperature during boreal winters (December through February 2001-2007). 
mesoscale convective systems with different phases of the $\mathrm{MJO}$ as it passes from the Indian Ocean to western Pacific Oceans.

(a)

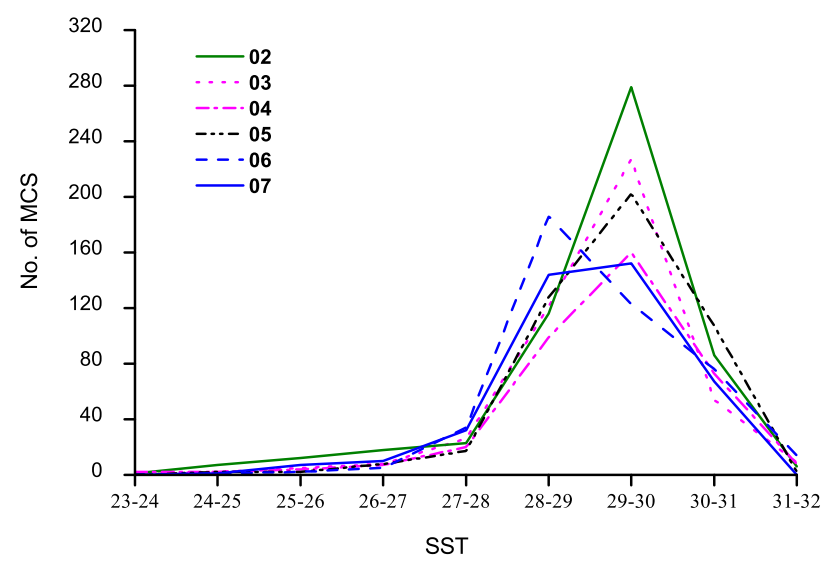

(b)

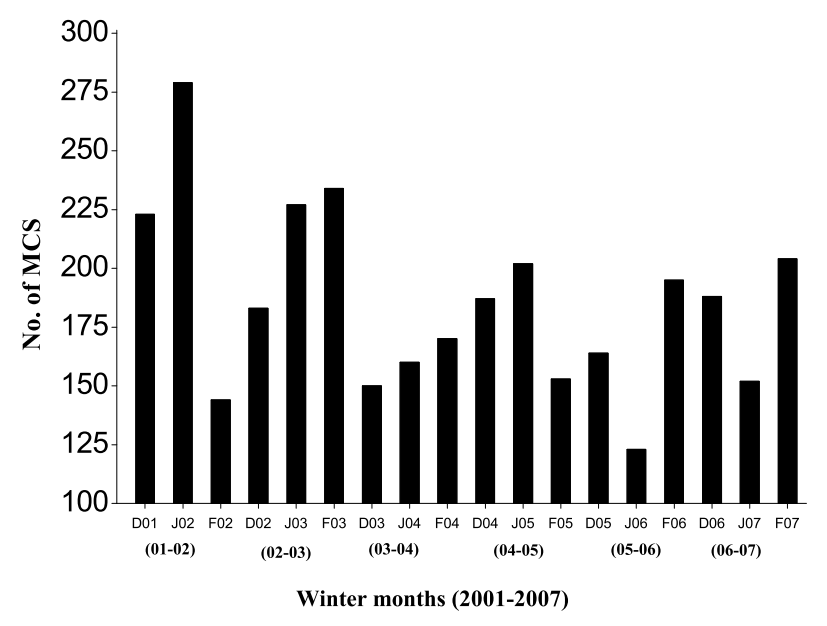

Fig. (4). Relationship between SST and MCS. (a) Total oceanic MCS for January from 2002 to 2007 as a function of SST; (b) MCS observations occurring over waters between 29 and $30^{\circ}$ Celsius during boreal winter months from 2001-2007.

\section{a. MJO and MCS Population}

In order to examine the relationship between MJO location and the frequency of mesoscale convective systems six composites are constructed with the five most negative pentad MJO index values and five most positive pentad MJO index values for the January period ( pentad 1-6) from 2001 through 2007 (Table 3). The indices are downloaded from the National Weather Service's Climate Prediction Center website (http://www.cpc.ncep.noaa.gov/products/precip/CW link/daily_mjo). The indices are centered at $70^{\circ} \mathrm{E}$ (Index 10), $80^{\circ} \mathrm{E}$ (Index 1), $100^{\circ} \mathrm{E}$ (Index 2), $120^{\circ} \mathrm{E}$ (Index 3), $140^{\circ} \mathrm{E}$ (Index 4) and $160^{\circ} \mathrm{E}$ (Index 5). The majority of the equatorial convection events occur in the eastern hemisphere and the indices covering the Indian Ocean to the West Pacific regions form the basis for this study. The indices were created by performing the Extended Empirical Orthogonal Function analysis on $200 \mathrm{hPa}$ velocity potential
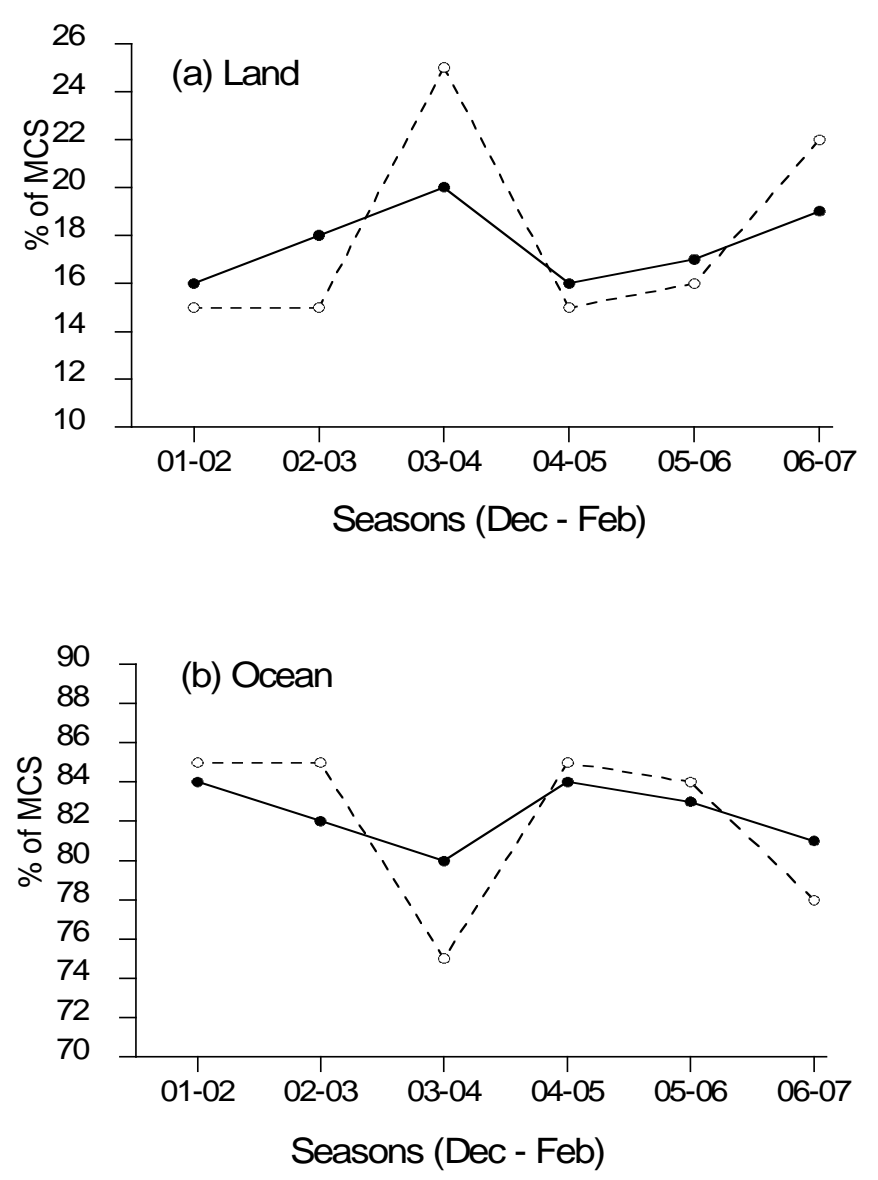

Fig. (5). Percent of MCSs occurring over land and ocean. (a) Percent of MCS over land; (b) Percent of MCS over ocean. Solid line represents December to February and dashed line indicates January only.

pentad anomalies equatorward of $30^{\circ} \mathrm{N}$ during ENSOneutral and weak ENSO winters (November-April) from 1979 to 2000 . Composites keyed on the convectively active phase of the ten MJO indices show both linear and nonlinear impacts of the MJO on the atmospheric circulation in the global domain. Negative index values indicate an active Madden-Julian Oscillation with enhanced convection over the given longitude and the positive values indicate the nonconvective passive phase of the MJO.

Fig. (8) demonstrates that during the active MJO phases in January the ratio of oceanic MCS to total MCS is 5-6\% more than for the passive $\mathrm{MJO}$ phases from $80^{\circ} \mathrm{E}$ to $140^{\circ} \mathrm{E}$. The differences between the phases were not found to be significant. However, the numbers of oceanic MCSs were significantly greater (95\% confidence according to t-test) when the MJO was active at $120^{\circ} \mathrm{E}$ (average $\left.=88.6\right)$ than when it was passive at $120^{\circ} \mathrm{E}$ (average $=66.2$ ). Further, there is a trend towards a greater proportion of oceanic MCS from the Indian Ocean to the West Pacific Ocean, peaking at $140^{\circ}$ E. Therefore, the spatial development of MCSs increases over the ocean as the MJO propagates eastward through the Maritime Continent.

\section{b. Pentad Time Series of the MJO Indices}

Fig. (9) shows the interannual variability of the MJO in the Indo-Pacific domain for January. The MJO index was 


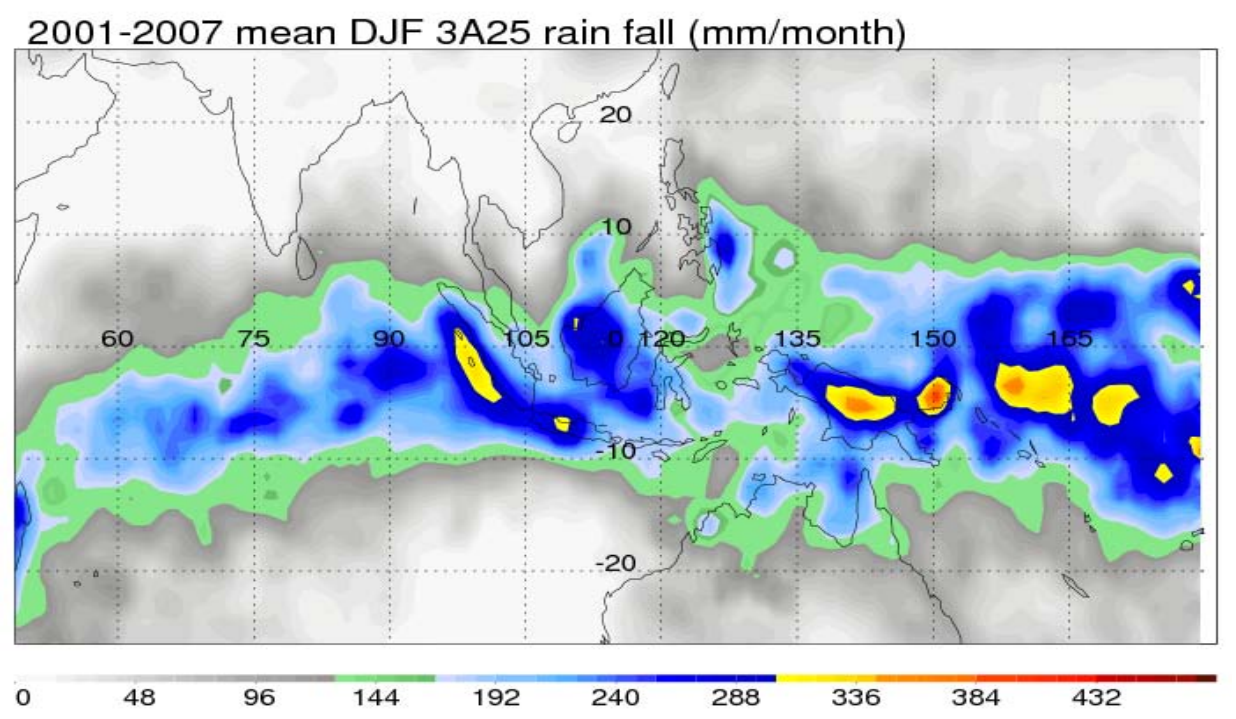

Fig. (6). December-January-February climatology of mean rain rate over the Indo-Pacific region. Multi-color scale is used for rain rate $(\mathrm{mm} / \mathrm{month})$. White $(0)$ represents absence of rainfall and dark red (432) denotes maximum rainfall intensity.

(a)

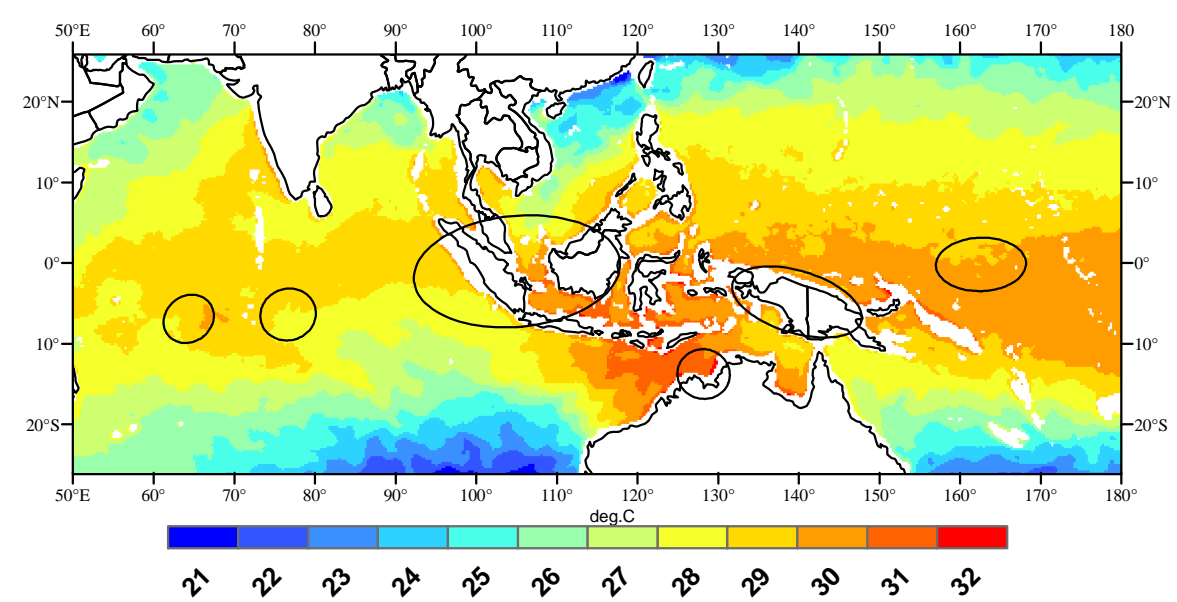

(b)

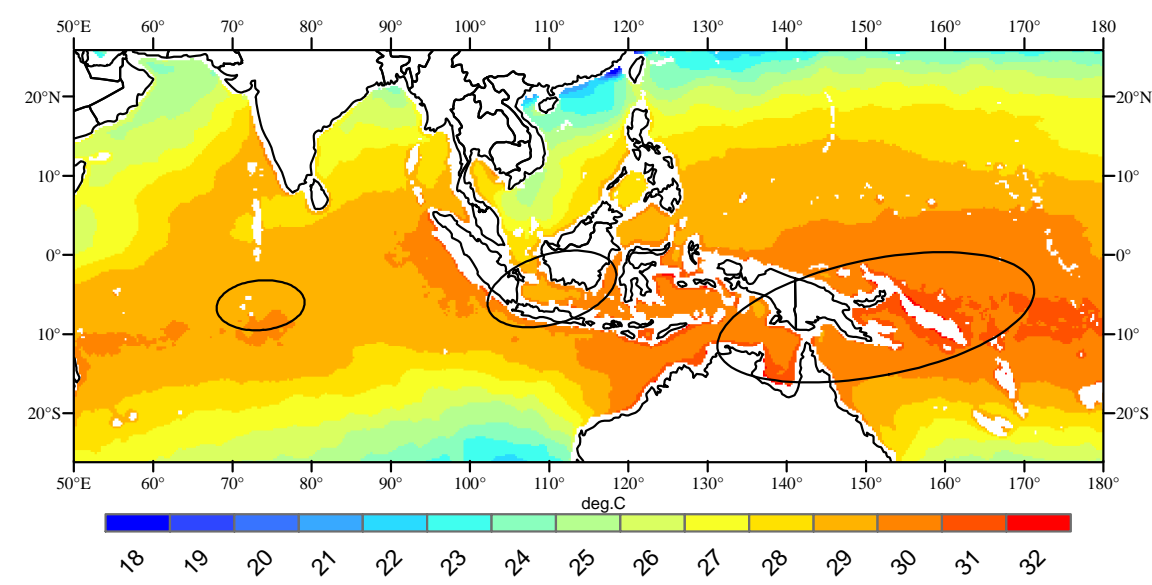

Fig. (7). Sea surface temperature and hot spots from 2001-2007. (a) December SST (color) and MCS hot spots (ellipses) from 2001 to 2006; (b) January SST and MCS hot spots from 2002-2007. 


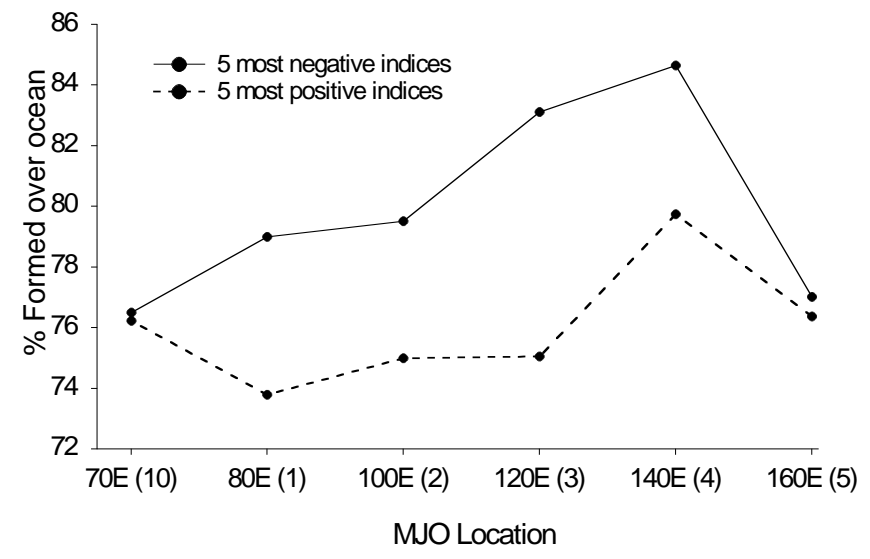

Fig. (8). Percentage of MCSs observed over ocean in January during phases of the MJO. Solid line denotes five pentads when the MJO index was most negative (active). Dashed line represents five pentads when the MJO index was most positive (passive). X-axis shows longitude and corresponding MJO indices are in parenthesis (see Table 3).

most positive during 2004 throughout the Indo-Pacific region. The magnitude of the inactive phase of $\mathrm{MJO}$ was greatest between $120^{\circ}$ and $140^{\circ} \mathrm{E}$ in the Maritime Continent and West Pacific Oceans (blue dotted line in Fig. (9)). The most negative (active) MJO index is observed in 2002 between $80^{\circ}$ and $100^{\circ} \mathrm{E}$ in the western Indian Ocean (black dotted line in Fig. (9)). It is proposed that the reduction in oceanic MCSs convection in January 2004 might be caused by the inactive MJO. The evidence of this hypothesis is supported by Fig. (5a, b, dashed line) which showed that the percentage of MCSs occurring over the land (ocean) was highest (lowest) in January 2004. The large number of MCSs over ocean in January 2002, when the MJO index was negative (active) may be a precursor to the 2002-03 El Nino.

\section{COMPOSITES AND MJO ANALYSIS OVER LAND AND OCEAN}

\section{a. Composites of Kernel Density Distribution and Hot Spots}

The kernel density distribution estimator is used to compute the absolute density of MCSs over a $2^{\circ}$ grid. The
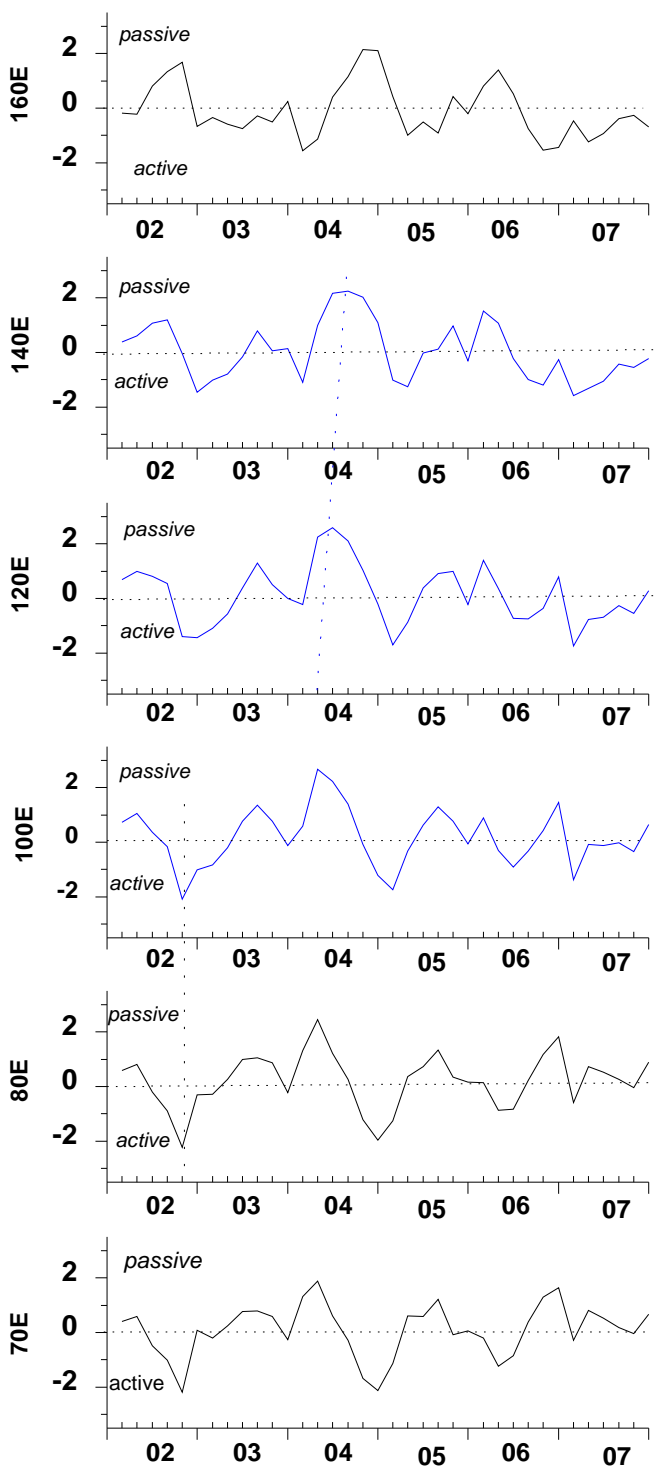

Fig. (9). Pentad time series of the MJO indices in the Indo-Pacific for January. Negative (positive) values on the Y-axis indicate active (passive) phase of the MJO. Blue curves distinguish Maritime Continent longlitudes. Dotted lines represent strong MJO phases.

Table 3. MJO Indices for January 2002 to 2007. Negative Pentad Index Values Represent Active Phase of MJO and Positive Index Values Indicate Passive (Inactive) Phase of MJO. The MJO Indices are Centered at $70^{\circ} \mathrm{E}, 8^{\circ} \mathrm{E}, \mathbf{1 0 0}^{\circ} \mathrm{E}, \mathbf{1 2 0}^{\circ} \mathrm{E}, \mathbf{1 4 0}^{\circ} \mathrm{E}$, and $160^{\circ} \mathrm{E}$ with Indices 10, 1, 2, 3, 4, and 5 Respectively

\begin{tabular}{|c|c|c|c|c|c|c|c|c|c|c|c|}
\hline $7^{\circ} \mathrm{E}(10)$ & Pentad & $80^{\circ} \mathrm{E}(1)$ & Pentad & $100^{\circ} \mathrm{E}(2)$ & Pentad & $120^{\circ} \mathrm{E}(3)$ & Pentad & $140^{\circ} \mathrm{E}(4)$ & Pentad & $160^{\circ} \mathrm{E}(5)$ & Pentad \\
\hline-2.19 & 20020123 & -2.23 & 20020123 & -2.09 & 20020123 & -1.74 & 20070103 & -1.58 & 20070103 & -1.55 & 20040103 \\
\hline-2.12 & 20040128 & -1.97 & 20040128 & -1.74 & 20050103 & -1.69 & 20050103 & -1.45 & 20020128 & -1.53 & 20060123 \\
\hline-1.67 & 20040123 & -1.26 & 20050103 & -1.38 & 20070103 & -1.43 & 20020128 & -1.31 & 20070108 & -1.44 & 20060128 \\
\hline-1.24 & 20060108 & -1.22 & 20040123 & -1.22 & 20040128 & -1.39 & 20020123 & -1.25 & 20050108 & -1.23 & 20070108 \\
\hline-1.14 & 20050103 & -0.90 & 20020118 & -1.01 & 20020128 & -1.10 & 20030103 & -1.19 & 20060123 & -1.13 & 20040108 \\
\hline 1.21 & 20050118 & 1.22 & 20040113 & 1.36 & 20030118 & 1.30 & 20030118 & 1.20 & 20020118 & 1.33 & 20020118 \\
\hline 1.29 & 20060123 & 1.31 & 20040103 & 1.39 & 20040118 & 1.39 & 20060103 & 1.51 & 20060103 & 1.39 & 20060108 \\
\hline 1.32 & 20040103 & 1.34 & 20050118 & 1.46 & 20060128 & 2.10 & 20040118 & 2.03 & 20040123 & 1.67 & 20020123 \\
\hline 1.63 & 20060128 & 1.82 & 20060128 & 2.22 & 20040113 & 2.24 & 20040108 & 2.17 & 20040113 & 2.10 & 20040128 \\
\hline 1.88 & 20040108 & 2.44 & 20040108 & 2.67 & 20040108 & 2.59 & 20040113 & 2.24 & 20040118 & 2.15 & 20040123 \\
\hline
\end{tabular}


estimator quantified differences between the five most negative and five most positive indices of $\mathrm{MJO}$ centered at $70^{\circ}, 80^{\circ}, 100^{\circ}, 120^{\circ}, 140^{\circ}$, and $160^{\circ} \mathrm{E}$ longitude for boreal winter (DJF) (Table 3). The hot spots of negative (active) phase of MJO are embedded into the distribution layer. The kernel density distribution difference when the $\mathrm{MJO}$ is at $70^{\circ}$ E longitude shows that during the active MJO composite MCS hot spots are predominantly located at $102^{\circ} \mathrm{E}$ and $3^{\circ} \mathrm{S}$ in the Maritime Continent (Fig. 10a). MCSs are more abundant in the East Indian Ocean and in the MC but less frequent in the West Pacific Ocean. For the MJO index centered at $80^{\circ} \mathrm{E}$ it is revealed that hot spots are at the same locations as Fig. (10a). For example, in both cases a cluster of MCS points are seen in the West Pacific Ocean centered at $146^{\circ} \mathrm{E}$ and $8^{\circ} \mathrm{S}$ off the coast of Papua New Guinea (Fig. 10a, b). At $100^{\circ} \mathrm{E}$ (Fig. 10c) the negative values and hot

(a)

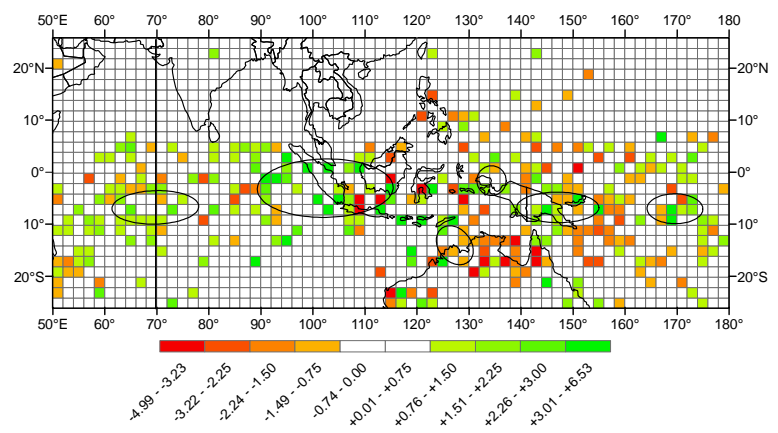

(c)

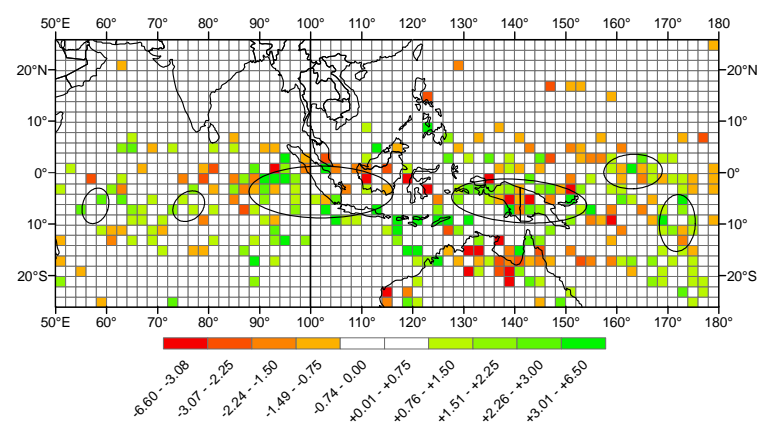

(e)

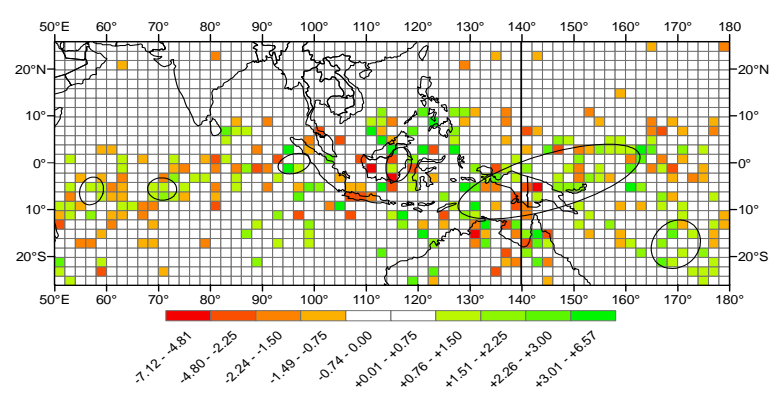

spots are largely located at the same location as Fig. (10a, b) but another hot spot is found in the West Pacific Ocean centered at $140^{\circ} \mathrm{E}$ and $4^{\circ} \mathrm{S}$. From the MJO composite it is demonstrated that MCS density is evidently higher off the Indonesian coast when the MJO is in the eastern Indian Ocean but MCSs begin to populate the western Pacific region as the MJO moves eastward. Therefore, high MCS density might be a consequence of the interaction of northeast winds over the South China Sea with local topography and localized patterns of deep convection and perhaps remotely connected with the Indian Ocean Dipole. This needs to be further investigated. Throughout the maps (Fig. 10) major hot spots and MJO densities are primarily observed over the East Indian Ocean and Java Sea.

The composite when the MJO is centered at $120^{\circ} \mathrm{E}$ suggests that the positive density differences and hot spots

( b)

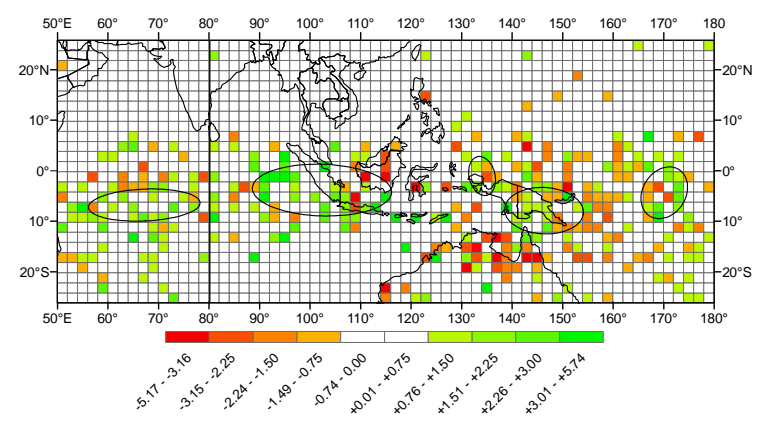

(d)

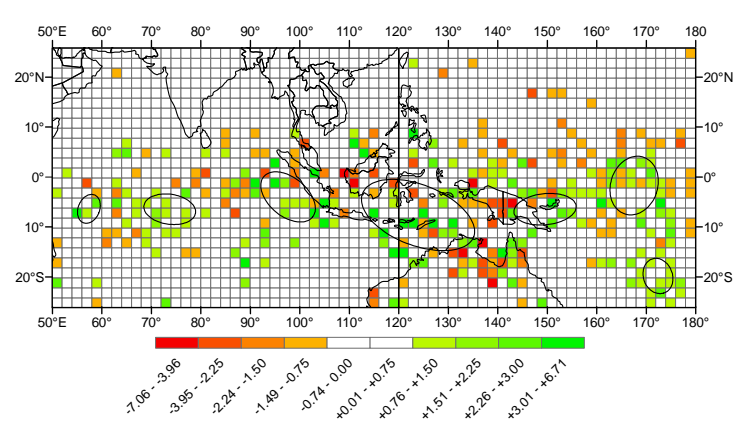

(f)

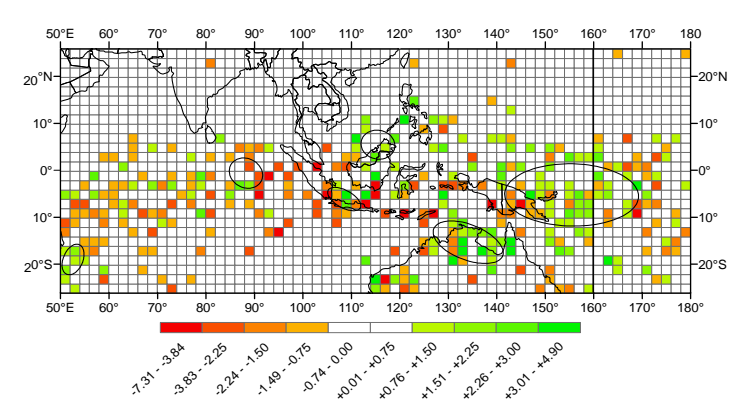

Fig. (10). Kernel density distribution differences and hotspots for January. Density difference (color) between five most negative and five most positive $\mathrm{MJO}$ indices at $70^{\circ}, 80^{\circ}, 100^{\circ}, 120^{\circ}, 140^{\circ}$, and $160^{\circ} \mathrm{E}$ longitude are presented in (a), (b), (c), (d), (e), and (f) respectively (see Table 3). The graduation of the colors denotes density differences from red (negative) to green (positive). The ellipses represent hot spots for the negative (active) composite of MJO index. Vertical black dark lines represent center of MJO indices. 
have moved towards the east and are predominantly positioned over the Flores Sea (Fig. 10d). Another hot spot has developed at $168^{\circ} \mathrm{E}$ and $2^{\circ} \mathrm{S}$ in the West Pacific Ocean. When the MJO is centered at $140^{\circ} \mathrm{E}$ the MCS density increases in the West Pacific and decreases in the Indian Ocean. The positive differences and hot spots are largely located at $145^{\circ} \mathrm{E}$ and $4^{\circ} \mathrm{S}$ (Fig. 10e). An additional hot spot has developed further south in the West Pacific Ocean $\left(17^{\circ} \mathrm{S}\right.$, $170^{\circ} \mathrm{E}$ ). When the MJO is centered at $160^{\circ} \mathrm{E}$ the densities and hot spots are shifted further to the east centered at $155^{\circ} \mathrm{E}$ and $5^{\circ} \mathrm{S}$ in the western Pacific Ocean. A sizeable number of grids with positive density differences and hot spots are observed in northern Australia (Fig. 10f). The spatial analysis of the top hotspot constructed from the five MJO composite difference maps, when the MJO is centered at $70^{\circ}$, $80^{\circ}, 100^{\circ}, 120^{\circ}, 140^{\circ}$, and $160^{\circ} \mathrm{E}$, are found in Table 4 . An eastward progression is clearly evident once the MJO reaches $100^{\circ} \mathrm{E}$.

Table 4. Centroid Locations of Largest Hot Spots for Negative (Active) Phases of MJO During January (see Fig. 10)

\begin{tabular}{|c|c|c|c|c|c|}
\hline $\begin{array}{c}\text { Location } \\
\text { (East) }\end{array}$ & Clusters & $\begin{array}{c}\text { Mean X } \\
\text { (lon.) }\end{array}$ & $\begin{array}{c}\text { Mean Y } \\
\text { (lat.) }\end{array}$ & $\begin{array}{c}\text { Rotation } \\
\text { (deg.) }\end{array}$ & $\begin{array}{c}\text { Points } \\
\text { Cluster }\end{array}$ \\
\hline \hline $70^{\circ}$ & 1 & $102^{\circ}$ & $-3^{\circ}$ & 89.0 & 127 \\
\hline $80^{\circ}$ & 1 & $102^{\circ}$ & $-4^{\circ}$ & 2.0 & 115 \\
\hline $100^{\circ}$ & 1 & $102^{\circ}$ & $-4^{\circ}$ & 0.30 & 99 \\
\hline $120^{\circ}$ & 1 & $124^{\circ}$ & $-7^{\circ}$ & 21.0 & 101 \\
\hline $140^{\circ}$ & 1 & $145^{\circ}$ & $-4^{\circ}$ & 77.0 & 127 \\
\hline $160^{\circ}$ & 1 & $155^{\circ}$ & $-5^{\circ}$ & 1.1 & 115 \\
\hline
\end{tabular}

\section{b. Relationship Between MJO and MCS, Volumetric Rain, Intensity Proxies, and Zonal Wind}

The relationship between MJO, when it is at $70^{\circ} \mathrm{E}$, and number of MCSs over ocean is found to be negative and significant $(p=0.04)$ (Fig. 11a). The relationship is moderately strong, however, the majority of the MCSs fall within -0.5 to +0.5 range of MJO demonstrating that most of the MJO signal is weak. The relationship between MJO and number of MCSs is a little stronger when the MJO is centered at $80^{\circ} \mathrm{E}$ (Fig. 11b).

We discuss here the relationships between the number and character of MCSs and the MJO intensities as the MJO moves eastward through the Maritime Continent (Fig. 12). The relationship between MJO and number of MCSs, median $85 \mathrm{GHz}$ PCT, and zonal wind were all found to be negative. The significance range was found between 1-3\% for all relationships. The highest negative relationship is found between MJO values and median $85 \mathrm{GHz}$ PCT at 0.41 with $p$ value of 0.01 (Fig. 12b). The zonal wind, $\mathrm{U}$, decreases as MJO values changes from negative to positive. All this taken together suggests that as the convection phase of the MJO enters the Maritime Continent the number of oceanic MCSs increase, they are more intense, and they are more likely associated with westerly winds. In fact, the mean wind is westerly 8 times when the MJO index is negative and only 2 times when the MJO index is positive (Fig. 12c). (a)

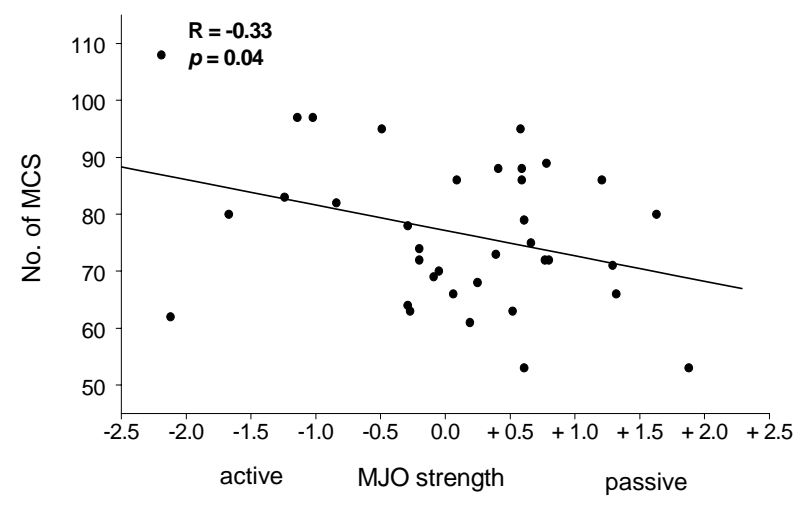

(b)

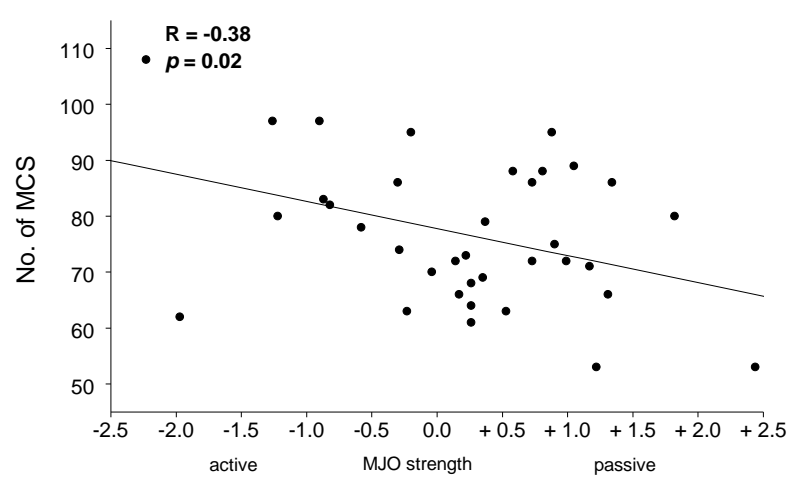

Fig. (11). MJO's influence on MCS count and intensity. (a) Number of observed MCS over ocean in relation to the $70^{\circ} \mathrm{E}$ index (Index 10); (b) Number of MCS observed over ocean in relation to the $80^{\circ} \mathrm{E}$ index (Index 1).

When the MJO index is centered at $120^{\circ} \mathrm{E}$ (over central Indonesia) the MJO-MCS relationships strengthen further. All the parameters show negative relationships with MJO. The highest relationship $-0.54(p=0.0006)$ is between the 85 PCT convective proxy and MJO (Fig. 13a). The zonal wind correlation with MJO strength is also strong $(-0.51)$ with $p$ value equaling 0.001 (Fig. 13b). This correlation over ocean is stronger than when the MJO was centered at $100^{\circ} \mathrm{E}$ longitude. This might be a signature of the rapid amplification of the convective systems as they pass through the Maritime Continent landmass area where a constant ascending branch of the Walker Circulation persists. The thermal forcing of the ocean-land contrast and presence of massive orography aids convection of moist air and release of heat.

Fig. (14) shows the MJO - MCS relationship when the MJO is centered at $140^{\circ} \mathrm{E}$ longitude. A moderate correlation is found with median $85 \mathrm{GHz}$ PCT over ocean and mean zonal wind surface (Fig. 14a, b). Interestingly, the MJO has a positive correlation with the number of MCSs observed over land (Fig. 14c). The relationship is found to be 0.36 at the 98 percent $(p=0.02)$ level of significance. Thus, only when the convective phase of the MJO reaches the eastern Maritime Continent is there a decrease in MCS observations over land. The correlations between MCS and MJO are found to be weaker as the MJO passes through the Maritime Continent to the western Pacific regions (Fig. 15a, b). Over 
land the number of MCS and their intensity decrease. This may be an indication of larger MCSs.

(a)

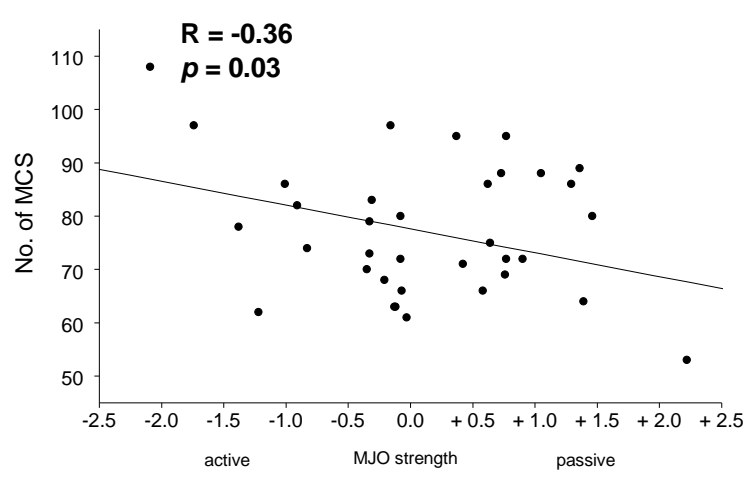

(b)

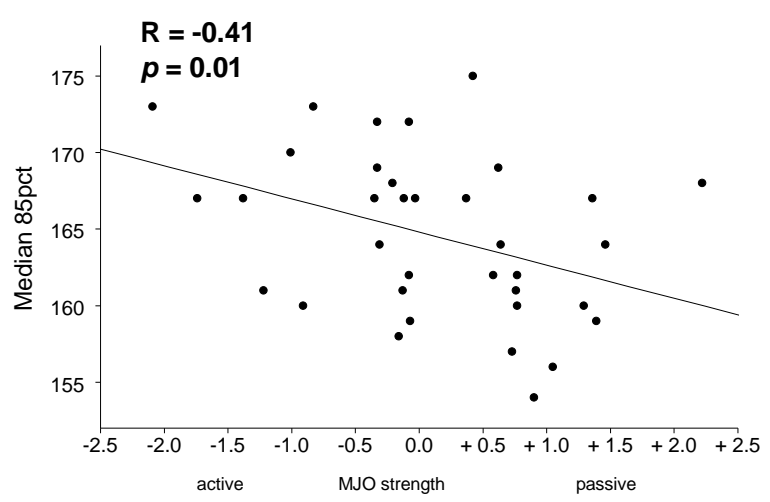

(c)

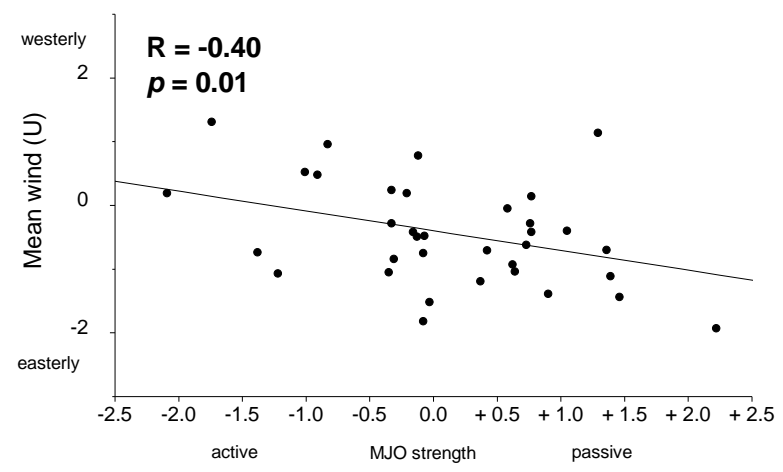

Fig. (12). MJO and precipitation feature parameters over ocean. (a) Number of MCS observed; (b) Median $85 \mathrm{GHz}$ PCT, and (c) Mean zonal wind (U) all in relation to the $100^{\circ} \mathrm{E}$ index (Index 2).

The explained variance of MJO to MCS counts and characteristics is between $11 \%$ and $29 \%$, which further suggests that other synoptic scale features - such as the Borneo vortex or cold surges - play an important role in the organization and intensity of these rain-producing systems. Further, this analysis does not take into account serial correlation. However, this is likely to be a small since the life-cycle of an individual MCS is less than five days.

\section{SUMMARY AND DISCUSSION}

From the density distribution it is observed that MCSs are commonly observed over the Maritime Continent and in the WPR. The systems tend to be preferentially found over ocean. Significant clusters are also seen along the vicinity of the coast.

(a)

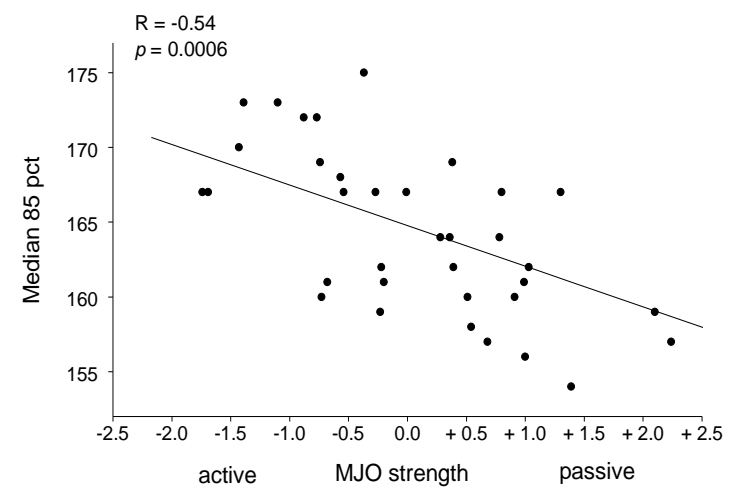

(b)

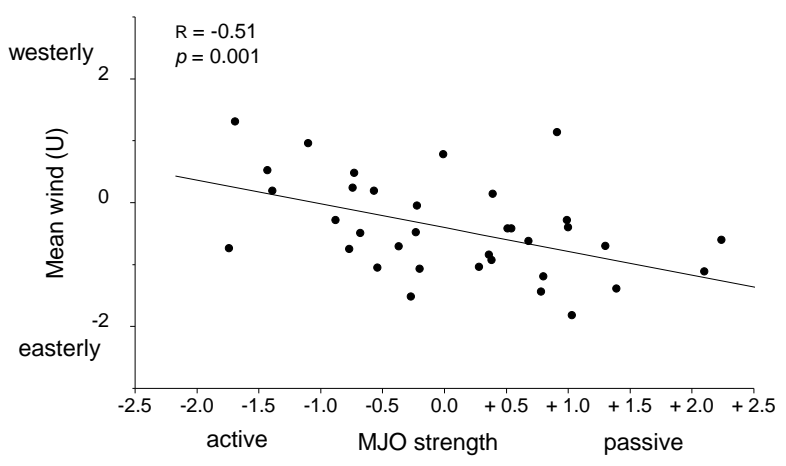

Fig. (13). MJO and precipitation feature parameters over ocean. (a) Median $85 \mathrm{GHz}$ PCT; (b) Mean zonal wind (U), all in relation to the $120^{\circ} \mathrm{E}$ index (Index 3).

The highest densities of the MCSs were observed in northern Australia, Papua New Guinea, both sides of Java Sea and Solomon Islands in the WPR. The hot spot analysis of boreal winter months from 2001 to 2007 suggests that the systems are more likely to be clustered in the eastern Indian Ocean in December and in the western Pacific Ocean in January, but more prevalent in the South Pacific Ocean (ranging from $4^{\circ}-10^{\circ} \mathrm{S}$ ) in February (not shown). This change in location may be a signal of the relation between the formation of MCS and the annual cycle of SST. The total number of MCSs was highest during the 2001-02 season.

Regarding the relationship between sea surface temperature and MCSs, the peak of the total MCSs distribution occurred between $29-30^{\circ} \mathrm{C}$. January shows the largest quantity of MCSs and the largest separation between January 2002 and the rest of the years occurred between 29 and $30^{\circ} \mathrm{C}$. The MCS observations peaked in January 2002 among all 18 months of the study period. There was an unusual abundance of MCSs over the equatorial eastern 
Indian Ocean and western Pacific Ocean during this month (not shown). These results are consistent with Curtis et al. [23] in the sense that an increase in storms in the IndoPacific led the mature 2002-03 El Nino by 12 months. The warm waters under the MCSs may be related to a coupled Madden-Julian Oscillation (MJO) process that convectively generates and maintains the storms. The western Pacific Ocean is warmer than the eastern Indian Ocean in January. However, the hot spots (ellipses) over ocean do not necessarily coincide with the warmest waters.

(a)

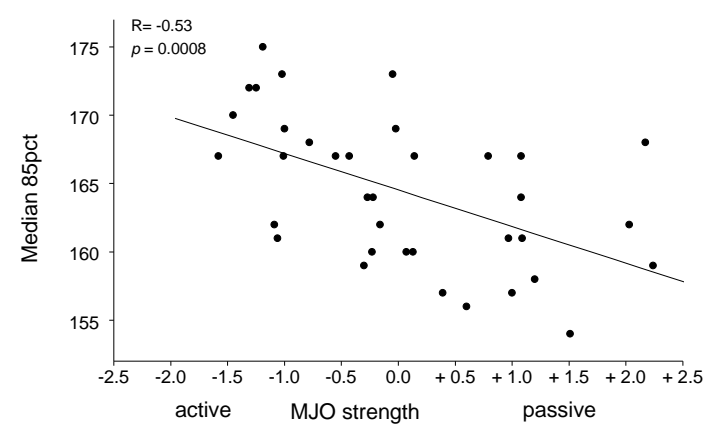

(b)

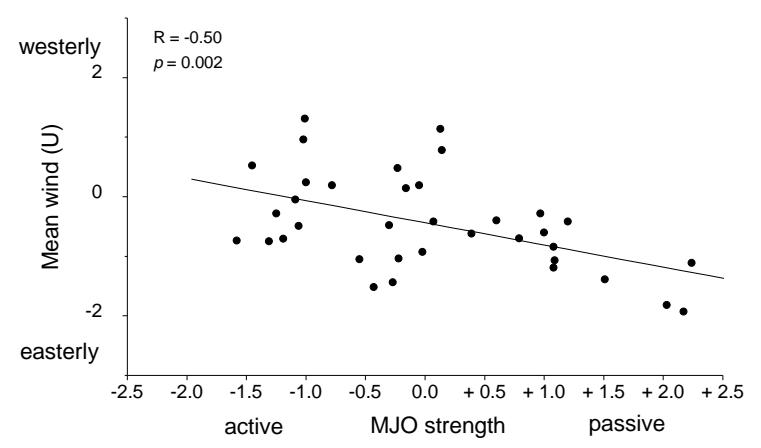

(c)

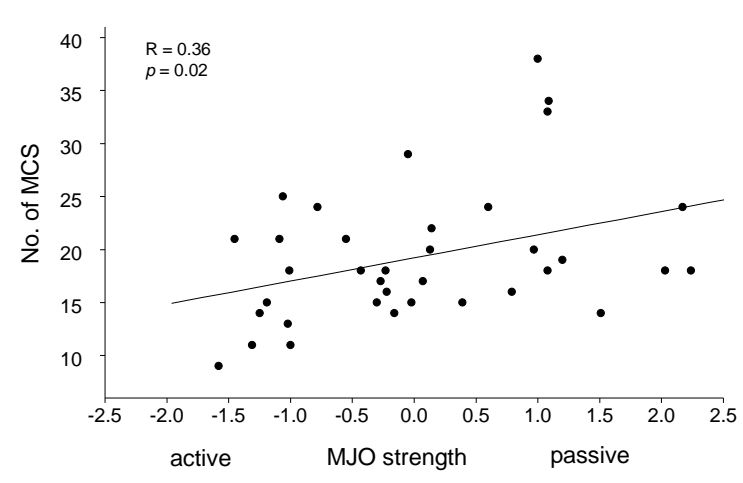

Fig. (14). MJO and precipitation feature parameters over ocean and land. (a) Median $85 \mathrm{GHz}$ PCT over ocean; (b) Mean zonal sea surface wind (U); (c) Number of MCS observed over land all in relation to the $140^{\circ} \mathrm{E}$ index (Index 4).

The DJF season composite of kernel density distribution depicts the spatial location of MCSs. The hot spots of MCSs during the negative phase of the MJO are clustered in the eastern Indian Ocean comprising Indonesia and Malaysia and western Indian Ocean when the MJO is centered at $70^{\circ}$ E. It is evident that a high density of MCS during the active phase of the MJO as compared to the passive phase is predominantly observed off the coast of Sumatra, Indonesia. The density and hot spots shift eastward with the MJO. In index $10\left(70^{\circ} \mathrm{E}\right)$, weak convection is present in the central Pacific, while enhanced convection of a growing event is evident over the Indian Ocean. At this point easterly wind anomalies may exist over the Indian Ocean, and westerly wind might exist over the Pacific Ocean. But in subsequent phases, as the MJO propagates eastward and passes through Maritime Continent the westerly wind bursts get stronger and strong clusters of MCSs are vivid in the western Pacific region. The convection in the Indian Ocean builds and moves to the east, and as it passes by the Australian landmass, shifts southward to be most concentrated at about $15^{\circ} \mathrm{S}$ (Index $\left.5 ; 160^{\circ} \mathrm{E}\right)$.

(a)

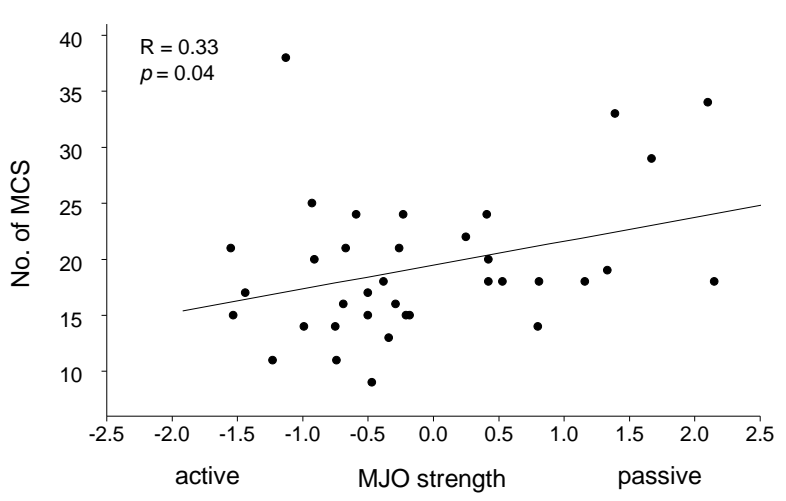

(b)

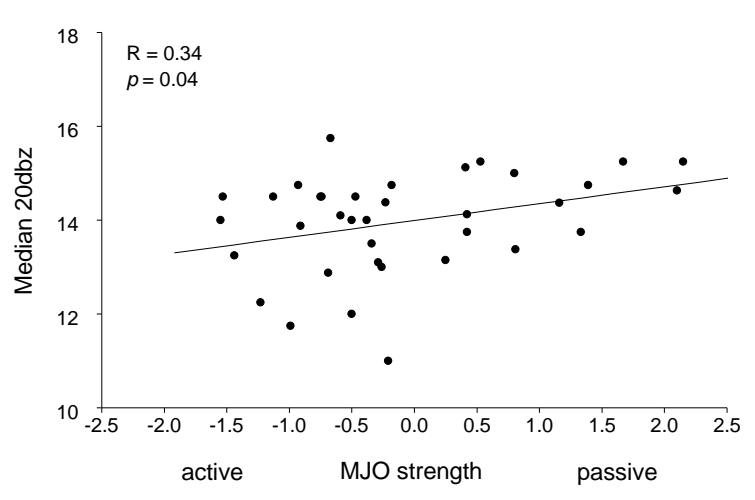

Fig. (15). MJO and precipitation feature parameters over land. (a) Number of MCS observed; (b) Median 20dBZ height $(\mathrm{km})$ all in relation to the $160^{\circ} \mathrm{E}$ index (Index 5).

The relationship between MJO and MCSs are found to be significant. Storm intensity increases when the active phase of the MJO is centered at $70^{\circ} \mathrm{E}$ in the Indian Ocean. Overall, negative relationships are found between number of MCSs, $85 \mathrm{GHz}$ PCT, and zonal wind with MJO index value. This means that when the convective phase of the MJO passes through the Maritime Continent the oceanic MCSs became more numerous, deliver more rainfall, became more intense, and are in an environment of westerly wind. In fact, the strongest correlation is observed for the zonal wind. This 
indicates that MCSs have an impact on westerly wind bursts during the eastward propagation of the MJO and the westerly wind bursts have been linked to the initiation of El Nino in the Pacific Ocean. The correlations with MCSs are first strong over the ocean then over the land when the MJO passes $140^{\circ} \mathrm{E}$. In these cases, the number of MCSs decreases over land when the MJO is active. In short, the MJO tends to enhance MCS development over the ocean ahead of its propagation and suppresses MCS development over land after it passes through the Maritime Continent.

\section{CONCLUDING REMARKS}

The Maritime Continent area is one of the major convective heat sources that drive the general circulation of the earth's atmosphere and massive orography powerfully aids convection of moist air and release of heat. An extensive literature review showed that no previous study considered to investigate the climatology of mesoscale convective systems and their intraseasonal to interannual variability in the Indo-Pacific region. The study is based on the overall hypothesis that the intraseasonal and interannual variability of mesoscale convective systems are largely dependent on the variation of sea surface temperature, and Madden-Julian Oscillation in the Indo-Pacific region. The time period for this study is the boreal winter season (DJF) for the 2001-02 to 2006-07 seasons, and the domain is bounded by $50^{\circ} \mathrm{E}$ to $180^{\circ}$ longitude and $26^{\circ} \mathrm{N}$ and $26^{\circ} \mathrm{S}$ latitude.

The findings of this study are consistent with previous studies and are outlined in the following scenario (see Fig. 1 for reference). Mesoscale convective systems are more likely found over ocean than land. Further, they have a peak in their spatial distribution between $28-29^{\circ} \mathrm{C}$. The MJO acts to organize the MCSs where in the active phase, SST increases leading to a greater frequency and intensity of MCSs. The MJO propagates the MCS clusters eastward in an environment of west wind. When the westerly winds reach the western Pacific, oceanic Kelvin waves are possible, and El Ninos can be initiated. The El Nino then leads to a drying of the Maritime Continent. During the passive phase, there are more MCSs over land, MCSs are less intense overall, and they tend to occur in an environment of easterly winds.

On the implications, the mesoscale convective systems in the Indo-Pacific region play an overarching role in the climate and agriculture sectors in Indonesia, Malaysia, and the Philippines. This study bears an implication for food security, coastal flooding and erosion, and ecosystems health. The quantitative prediction of ENSO effects on rice production can provide an additional tool for managing food security in the region. Higher rainfall induces more erosion that causes siltation of dams and harbors resulting in raised river beds and frequent flooding during wet months. Also intense surface runoff causes severe erosion along the exposed hillsides. Increased depth of inundation along the coast is due to heavy precipitation affecting coastal infrastructure and encroaching public and private properties. Also extreme precipitation might lead to an excess of nutrients which can reduce overall productivity. In this regards, island countries with increasingly large coastal populations are vulnerable to climate extremes. Therefore, it is important to understand the climate science and interacting linkages between phenomena from different space and time scales.

\section{ACKNOWLEDGEMENTS}

The financial support for this study was provided by National Aeronautics and Space Administration Precipitation Measurement Mission grant No. NN04GB35G and East Carolina University Research Development Award Grant. Dr. Chuntao Liu, the Department of Meteorology of University of Utah, provided Tropical Rainfall Measuring Mission precipitation feature datasets. Authors would gratefully acknowledge his contribution to this paper.

\section{REFERENCES}

[1] Lengaigne M, Boulanger JP, Menkes C, et al. The March 1997 westerly wind event and the onset of the 1997/98 El Nino: Understanding the role of the atmospheric response. J Clim 2003; 16: 3330-43.

[2] Curtis S, Salahuddin A. Interannual changes of 20-50 and 50-100 day climate variability in the Indo-Pacific sector in Austral summer. J Meteorol Soc Jpn 2006; 84: 567-79.

[3] Houze RA. Cloud Dynamics. California, USA: Academic Press 1993.

[4] Nesbitt SW, Zipser EJ, Cecil DJ. A census of precipitation features in the Tropics using TRMM: Radar, ice scattering, and lightning observations. J Clim 2000; 13: 4087-106.

[5] Nesbitt SW, Cifelli R, Rutledge SA. Storm morphology and rainfall characteristics of TRMM precipitation features. Mon Weather Rev 2006; 134: 2702-21.

[6] Toracinta ER, Zipser EJ. Lighting and SSM/I-Ice-Scattering mesoscale convective systems in the global tropics. J Appl Meteorol 2001; 40: 983-1002.

[7] Zipser EJ, Cecil DJ, Liu C, Nesbitt SW, Yorty DP. Where are the most intense thunderstorms on earth? Bull Am Meteorol Soc 2006; 87: 1057-71.

[8] Madden RA, Julian PR. Detection of a 40-50 day oscillation in the zonal wind in the tropical pacific. J Atmos Sci 1971; 28: 702-8.

[9] Madden RA, Julian PR. Observations of the 40-50 day tropical oscillation-a review. Mon Weather Rev 1994; 122: 814-35.

[10] Chang CP, Harr PA, Chen H-J. Synoptic disturbances over the equatorial South China Sea and western maritime continent during boreal winter. Mon Weather Rev 2005; 133: 489-503.

[11] Tangang FT, Juneng L, Salimun E, et al. On the roles of the northeast cold surge, the Borneo vortex, the Madden-Julian Oscillation, and the Indian Ocean Dipole during the extreme 2006/2007 flood in southern Peninsular Malaysia. Geophys Res Lett 2008; 35: L14S07; doi:10.1029/2008GL033429.

[12] Tang Y, Yu B. MJO and its relationship to ENSO. J Geophys Res 2008; 113: D14106; doi:10.1029/2007JD009230.

[13] Vialard J, Foltz GR, McPhaden MJ, Duvel JP, Montegut Cde B. Strong Indian Ocean sea surface temperature signals associated with the Madden-Julian Oscillation in late 2007 and early 2008. Geophys Res Lett 2008; 36: L19608; doi:10.1029/2008GL035238.

[14] Curtis S, Huffman GJ, Adler RF. Precipitation anomalies in the tropical Indian Ocean and their relation to the initiation of El Nino. Geophys Res Lett 2002; 29: 1441-55.

[15] Spencer RW, Goodman HM, Hood RE. Precipitation retrieval over land and ocean with the SSM/I: Identification and characteristics of the scattering signal. J Atmos Oceanic Technol 1989; 6: 254-73.

[16] Rosenblatt M. Remarks on some nonparametric estimates of a density function. Ann Math Stat 1956; 27: 832-5.

[17] Whittle P. On the smoothing of probability density functions. J R Stat Soc 1958; 20: 334-43.

[18] Parzen E. On estimation of a probability density function and mode. Ann Math Stat 1962; 33: 1065-76.

[19] Block C. STAC hot spot areas: a statistical tool for law enforcement decisions, in Proceedings of the Workshop on Crime Analysis through Computer Mapping, Criminal Justice Information Authority. Chicago, IL 1994. 
[20] Block R, Block CR. Space, place and crime: hot spot areas and hot places of liquor-related crime. In Crime Places in Crime Theory. Eck J, Weisburd D, Eds. Rutgers Crime Prevention Studies Series. Newark: Criminal Justice Press 1995.

[21] Schumacher C, Houze RA Jr. Stratiform rain in the tropics as seen by the TRMM Precipitation Radar. J Clim 2003; 16: 1739-56.
[22] Chou MD, Chou SH. Influence of transient atmospheric circulation on the surface heating of the western Pacific warm pool. Geophys Res Lett 2005; 32: L05706; doi:10.1029/2004GL021674.

[23] Curtis S, Adler RF, Huffman GJ, Gu G. Westerly wind events and precipitation in the eastern Indian Ocean as predictors for El Nino: climatology and case study for the 2002-03 El Nino. J Geophys Res 2004; 109: 20104; doi:10.1029/2004JD004663

(c) Salahuddin and Curtis; Licensee Bentham Open.

This is an open access article licensed under the terms of the Creative Commons Attribution Non-Commercial License (http://creativecommons.org/licenses/by$\mathrm{nc} / 3.0 /$ ) which permits unrestricted, non-commercial use, distribution and reproduction in any medium, provided the work is properly cited. 